\title{
Editorial - Epidemiology
}

\section{Epidemiology and public health in primary care: looking back and forward -30 years after Alma Ata}

\author{
Cyprian Okoro \\ Epidemiology Editor
}

Epidemiology is the basic science of public health, and an epidemiologist has been described as someone with a brilliant mind but dirty hands! The dirty hands come from the essential ability to count, collate and analyse raw data in order to give meaning to it. This ability to synthesise research evidence and transform health service activity data into simple and clear information for health service managers is what makes epidemiology an essential link between research and health policy.

One of the key aims of the London Journal of Primary Care is to facilitate the transfer of good research evidence and best practice into London primary care, as well as helping to build up the evidence base to support clinical practice from a variety of sources including local audits and experiential learning. As the Epidemiology Editor, I look forward to reviewing articles that are grounded in both qualitative and quantitative research methodology, but will also encourage articles with simpler methodologies where the focus is on improving clinical quality and systems.

London is a unique city - not only in the financial, arts and multi-cultural realms, but in its contribution to the history and development of epidemiology and public health in the United Kingdom and rest of the world. It is not surprising therefore that London is home to some 'national treasures' ranging from great medical and social science institutions, research centres, health observatories, prisons, air and sea ports to unique and prestigious government departments. These have one thing in common - they are a rich source of routine data which could be used to improve the health of Londoners in various ways ranging from infectious disease surveillance, to monitoring trends in patterns and distribution of morbidity, mortality and health inequalities across the capital.

The epidemiology team will seek to build collaborations between the journal and these London institutions so that the journal becomes an important vehicle for disseminating information relevant to the health of Londoners. We will also welcome articles from other metropolitan cities across the world with similar demographic profiles to that of London.

This year marks the 30th anniversary of the WHO declaration of the Alma Ata principles which emphasised the central role of primary health care (PHC) in any given health system. Many of the issues specifically addressed in that declaration such as the need for appropriate social and cultural systems to support health care, involving individuals and communities in health care decisions, the need for affordable health care, health inequalities, the link between poverty and health and the menace from vaccine preventable childhood illnesses are still very much important health issues in London today. The next issue of the London Journal of Primary Care will focus on the Alma Ata declaration and I would like to invite articles that demonstrate relevant lessons learnt across primary care from different perspectives.

That includes articles that look forward using these lessons, derived from the familiar research methods to case studies and relevant experiences over the past 30 years in settings relevant to a metropolitan city.

\section{ADDRESS FOR CORRESPONDENCE:}

Dr Cyprian Okoro

Consultant in Public Health Medicine

Ealing PCT

1 Armstrong way

Southall

Middlesex

UB2 4SA 